\title{
Numerical investigation on the performance, sustainability, and efficiency of the deep borehole heat exchanger system for building heating
}

\author{
Chaofan Chen ${ }^{1,2}$, Haibing Shao ${ }^{1,3^{*}} \mathbb{0}$, Dmitri Naumov ${ }^{1}$, Yanlong Kong ${ }^{4}$, Kun Tu $^{5,6}$ and Olaf Kolditz ${ }^{1,2}$
}

${ }^{*}$ Correspondence:

haibing.shao@ufz.de

${ }^{1}$ Helmholtz Centre

for Environmental Research

(UFZ), Permoserstr. 15,

04318 Leipzig, Germany

Full list of author information

is available at the end of the

article

\begin{abstract}
In densely inhabited urban areas, deep borehole heat exchangers (DBHE) have been proposed to be integrated with the heat pump in order to utilize geothermal energy for building heating purposes. In this work, a comprehensive numerical model was constructed with the OpenGeoSys (OGS) software applying the dual-continuum approach. The model was verified against analytical solution, as well as by comparing with the integrated heat flux distribution. A series of modeling scenarios were designed and simulated in this study to perform the DBHE system analysis and to investigate the influence of pipe materials, grout thermal conductivity, geothermal gradient, soil thermal conductivity, and groundwater flow. It was found that the soil thermal conductivity is the most important parameter for the DBHE system performance. Both thermally enhanced grout and the thermally insulated inner pipe will elevate the outflow temperature of the DBHE. With an elevated geothermal gradient of $0.04^{\circ} \mathrm{C} \mathrm{m}^{-1}$, the short-term sustainable specific heat extraction rate imposed on the DBHE can be increased to $150-200 \mathrm{~W} \mathrm{~m}^{-1}$. The quantification of maximum heat extraction rate was conducted based on the modeling of 30-year-long operation scenarios. With a standard geothermal gradient of $0.03{ }^{\circ} \mathrm{C} \mathrm{m}^{-1}$, the extraction rate has to be kept below $125 \mathrm{~W} \mathrm{~m}^{-1}$ in the long-term operation. To reflect the electricity consumption by circulating pump, the coefficient of system performance (CSP) was proposed in this work to better quantify the system efficiency. With the typical pipe structure and flow rate specified in this study, it is found that the lower limit of the DBHE system is at a CSP value of 3.7. The extended numerical model presented in this study can be applied to the design and optimization of DBHE-coupled ground source heat pump systems.
\end{abstract}

Keywords: Deep borehole heat exchanger system, Performance, Sustainability, Temperature recovery ratio, Coefficient of system performance (CSP)

\section{Introduction}

With the growing demand on renewable energy all over the world, geothermal heating and cooling is increasingly utilized by applying borehole heat exchanger (BHE) coupled ground source heat pump (GSHP) systems. One of the factors preventing the further application of GSHP system in densely populated urban areas is the limiting land surface for installing the BHEs. Therefore, deeper boreholes with a depth of $2302 \mathrm{~m}$ have been 
drilled and tested to satisfy the high thermal load from buildings (Kohl et al. 2002). In northern China, geothermal heat has been considered as a clean and renewable resource for building heating and it is continuously promoted by the government (Ni et al. 2015; Wang et al. 2017). In mega-cities, such as Xi'an and Harbin, pilot projects have been developed with deep borehole heat exchangers (DBHE) of more than $2 \mathrm{~km}$ deep. They are coupled with heat pumps to supply heating to office buildings and shopping malls. Different from the U-tube type BHE typically utilized in shallow geothermal projects, the coaxial pipe is employed in the deep boreholes to extract high-quality geothermal resources, taking advantage of its large heat transfer surface area and easy installation. As the surrounding soil and rock are hotter than the DBHE outer surface, circulating fluid is normally injected through the annulus part downwards and returned from the inner pipe, so that the heat exchange between soil and outer pipe is enhanced and the heat loss from the inner pipe can be minimized (Cai et al. 2018; Holmberg et al. 2016).

Through lab and field experiments, impact of thermal properties around and inside the standard BHE has been investigated by multiple researchers. Acuña and Palm (2013) presented results from three distributed thermal response tests (DTRT) carried out on two coaxial pipe-in-pipe BHEs at different flow rates. Wagner et al. (2014) concluded that advection-influenced DTRT could potentially be used to determine integral hydraulic conductivity of the subsurface. Soldo et al. (2016) measured the carrier fluid temperature along the BHE using a fiber optic cable placed inside the BHE pipes that are located in the city of Osijek. They pointed out the ground thermal conductivity for specific geological settings could be determined from the data gathered from the fiber optic cable. In order to investigate key parameters affecting the system performance, Beier and Holloway (2015), Lhendup et al. (2014) evaluated the DBHE thermal performance and highlighted the importance of thermal conductivity of the inner pipe, as well as the discharge rate of fluid carrier. Generally, the system can be used for at least 20-30 years when constructed properly, which is the advantage of geothermal energy. However, it is very important to estimate and prognosis the sustainability of such system during its design phase. When overloaded for long period of time, outflow temperature of the DBHE will decrease significantly to even lower than $4{ }^{\circ} \mathrm{C}$, which will cause the heat pump to shut down. For example, Galgaro et al. (2015) analyzed the system located in north-east Italy with respect to its thermal impact on underground and groundwater temperature. Dijkshoorn et al. (2013) evaluated the feasibility of an installation of coaxial deep BHE for space heating and cooling the building of the university in the center of the city Aachen, Germany. The simulation results indicated that after a 20 -year period of operation, the DBHE outflow temperature will be too low to drive the adsorption unit for cooling.

In literature, the sustainability analysis and temperature prediction of DBHE are conducted either by analytical solutions or numerical simulations. There are several analytical or semi-analytical solutions established for this purpose ( $\mathrm{Li}$ and Lai 2015). It ranges from line source models to transient heat transfer models. For example, Gordon et al. (2017) and Rivera et al. (2016) developed specific solutions for the coaxial type BHE. In these analytical solutions, the initial soil temperature is regarded as a constant and homogeneously distributed value. For shallow geothermal systems down to a depth less than $120 \mathrm{~m}$, such assumptions are appropriate. However, for a 2-km DBHE, the soil temperature at the bottom can be $60^{\circ} \mathrm{C}$ higher than the surface, even following a moderate 
natural geothermal gradient. In this case, the constant soil temperature becomes unrealistic. It is also important to notice that the subsurface geological structure is often heterogeneous, with aquifers and sediment layers of different degrees of permeability lying beneath there. When comparing the 2D (Bu et al. 2012; Fang et al. 2018) and 3D (Kong et al. 2017) numerical models, Cui et al. (2018) summarized that the 3D models are advantageous because the working fluid temperature can be accurately simulated and there is more freedom to describe the influence of groundwater flow on system performance. Le Lous et al. (2015) investigated the impact of subsurface physical parameters, DBHE materials, and operating settings. The performance and feasibility of using DBHE for energy storage were also evaluated by Welsch et al. (2016) through a detailed comparison comprising more than 250 different numerical storage models. In order to analyze the performance difference between conventional and unconventional deep geothermal well concepts, Falcone et al. (2018) performed various numerical simulations to optimize the BHE design and to enhance the heat exchange with the surrounding formation. Shi et al. (2018) presented a transient state fluid flow and heat transfer model considering natural convection for down-hole coaxial heat exchanger system and concluded that this system could be more suitable for the geothermal field with smaller porosity. It is aware in the community that $3 \mathrm{D}$ numerical simulations are often computationally expensive. Therefore, their application in the long-term performance analysis was only investigated for the sustainability of shallow U-type BHE (Hein et al. 2016b; Lazzari et al. 2010) and the impact of latent heat (Zheng et al. 2016). Wu et al. (2019) performed simulation on a new single-well circulation (SWC) groundwater heat pump system. Tang and Nowamooz (2018) used a hydrothermal numerical model to predict seasonal hydrothermal fluctuations in Illkirch for 5 years. All these numerical studies are concentrated on the shallow systems. Due to the large size of 3D mesh, numerical analysis on long-term DBHE system performance is computationally more demanding and hence has been barely reported in literature.

In the aforementioned studies, principle and performance of the BHE system were investigated based on single or a few parameters, while sustainability and efficiency analysis was difficult to perform due to the high demand on computational resources. One of the potential solutions is to apply the dual-continuum approach (Al-Khoury et al. 2010; Diersch et al. 2011a; Diersch 2013), in which the soil compartment is discretized with 3D prism elements and the DBHEs are represented by $1 \mathrm{D}$ elements. The heat transport governing equations in the soil and within the DBHE are different but assembled into one global linear equation. As a result, there is no need to fully discretize every component in the DBHE so that the number of total elements can be significantly decreased. Based on the dual-continuum approach, the DBHE model was developed in the OpenGeoSys (OGS) software and the heat pump efficiency change was integrated. The numerical model was first verified against analytical solution proposed by Beier et al. (2014), and also characterized using the measured parameters obtained from a geothermal project in northern China. Further, the heat flux variation over depth was calculated and analyzed. After that, the system performance was systematically investigated with respect to the pipe materials, grout thermal conductivity, geothermal gradient, soil thermal conductivity, and groundwater flow. The long-term scenarios of 30 years were simulated to clarify the sustainability of such system based on the quantification of temperature 
evolution and temperature recovery ratio every year. In addition, the efficiency of operating such system was assessed by the coefficient of system performance (CSP), in which electricity consumed by the circulating pump was explicitly considered. Conclusions are finally drawn in the end regarding the key parameters on performance, efficiency, and sustainability of DBHE-coupled GSHP system.

\section{Methods}

In this work, the open-source finite element simulator OpenGeoSys (OGS) (Kolditz et al. 2012; Shao et al. 2016) has been applied to study the long-term behavior of the DBHE system. The algorithm behind this numerical model was based on the dual-continuum approach proposed by Al-Khoury et al. (2010) and extended by Diersch et al. (2011a, b) and Diersch (2013).

\section{Dual-continuum approach}

For the heat transfer process inside and around the DBHE, the modeling domain is divided into two continua. For the soil part, it is discretized with 3D triangular prism elements, while the DBHE part is represented by $1 \mathrm{D}$ line elements as the second continuum (see Fig. 1). The heat transfer rate within the DBHE and soil is calculated following the thermal capacity-resistor network, i.e., the amount of heat flux is dependent on the temperature difference (cf. Diersch 2013).

With the soil-specific heat capacity $c_{\mathrm{s}}$, soil density $\rho_{\mathrm{s}}$, and soil porosity $\epsilon$, the soil temperature is dominated by the following governing equation considering both the heat convection and conduction,

$$
\frac{\partial}{\partial t}\left[\epsilon \rho_{\mathrm{f}} \mathcal{C}_{\mathrm{f}}+(1-\epsilon) \rho_{\mathrm{s}} \mathcal{c}_{\mathrm{s}}\right] T_{\mathrm{s}}+\nabla \cdot\left(\rho_{\mathrm{f}} \mathcal{C}_{\mathrm{f}} \mathbf{v}_{\mathbf{f}} T_{\mathrm{s}}\right)-\nabla \cdot\left(\Lambda_{\mathrm{s}} \cdot \nabla T_{\mathrm{s}}\right)=H_{\mathrm{s}},
$$

where $c_{\mathrm{f}}, \rho_{\mathrm{f}}$, and $\mathbf{v}_{\mathbf{f}}$ refer to the specific heat capacity, density, and Darcy velocity of groundwater, respectively. $\Lambda_{\mathrm{S}}$ denotes the tensor of thermal hydrodynamic dispersion and $H_{\mathrm{s}}$ represents the heat source and sink term. The heat flux between soil and DBHE is then calculated by the following equation:
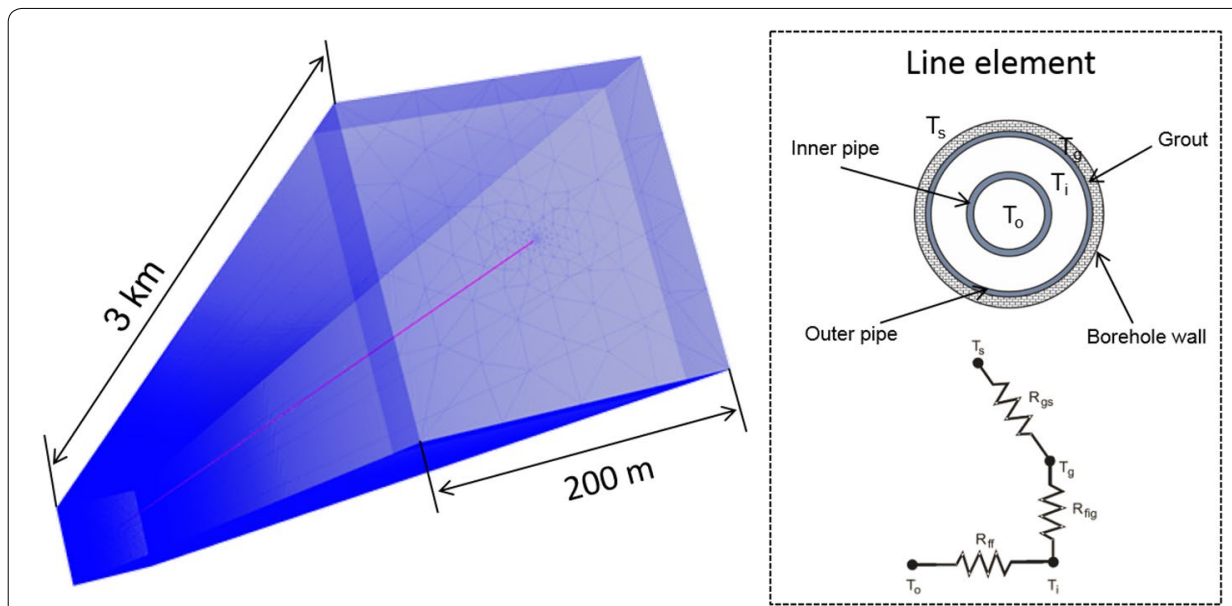

Fig. 1 DBHE implementation in numerical model 


$$
-\left(\Lambda_{\mathrm{s}} \cdot \nabla T_{\mathrm{s}}\right)=q_{n} T_{\mathrm{s}} .
$$

For coaxial type of DBHEs, three governing equations were integrated, with the primary variable $T_{\mathrm{i}}, T_{\mathrm{o}}$, and $T_{\mathrm{g}}$ representing the inflow, outflow, and grout temperatures. For the DBHE of coaxial pipe with annual (CXA) inlet, the heat transport process of inflow fluid is mainly dominated by the heat convection of circulating fluid (refrigerant) $r$ with flow velocity $\mathbf{v}_{\mathbf{i}}$.

$$
\begin{aligned}
& \rho_{\mathrm{r}} c_{\mathrm{r}} \frac{\partial T_{\mathrm{i}}}{\partial t}+\rho_{\mathrm{r}} c_{\mathrm{r}} \mathbf{v}_{\mathbf{i}} \cdot \nabla T_{\mathrm{i}}-\nabla \cdot\left(\Lambda_{\mathrm{r}} \cdot \nabla T_{\mathrm{i}}\right)=H_{\mathrm{i}} \text { in } \Omega_{\mathrm{i}} \\
& \quad \text { with Cauchy type of BC: } \\
& q_{n T_{\mathrm{i}}}=-\Phi_{\mathrm{fig}}\left(T_{\mathrm{s}}-T_{\mathrm{i}}\right)-\Phi_{\mathrm{ff}}\left(T_{\mathrm{o}}-T_{\mathrm{i}}\right) \text { on } \Gamma_{\mathrm{i}}
\end{aligned}
$$

As for the inner pipe, where the outflow stream is going upwards, the governing equation is written,

$$
\begin{aligned}
& \rho_{\mathrm{r}} c_{\mathrm{r}} \frac{\partial T_{\mathrm{o}}}{\partial t}+\rho_{\mathrm{r}} c_{\mathrm{r}} \mathbf{v}_{\mathrm{o}} \cdot \nabla T_{\mathrm{o}}-\nabla \cdot\left(\Lambda_{\mathrm{r}} \cdot \nabla T_{\mathrm{o}}\right)=H_{\mathrm{o}} \text { in } \Omega_{\mathrm{o}} \\
& \text { with Cauchy type of BC: } \\
& \quad q_{n} T_{\mathrm{o}}=-\Phi_{\mathrm{ff}}\left(T_{\mathrm{i}}-T_{\mathrm{o}}\right) \text { on } \Gamma_{\mathrm{o}}
\end{aligned}
$$

where the hydrodynamic thermodispersion tensor can be written as,

$$
\Lambda_{\mathrm{r}}=\left(\lambda_{\mathrm{r}}+\rho_{\mathrm{r}} c_{\mathrm{r}} \beta_{\mathrm{L}}\left\|\nu_{\mathrm{r}}\right\|\right) \mathbf{I}
$$

In the above equation, $\lambda_{\mathrm{r}}, \rho_{\mathrm{r}}, c_{\mathrm{r}}$ denote the heat conductivity, density, and specific heat capacity of circulating fluid. $\beta_{\mathrm{L}}$ refers to the longitudinal heat dispersivity, and $\mathbf{I}$ is the unit matrix. For the grout zone surrounding the outer pipe, the heat transport process is assumed to be dominated only by the heat conduction in it.

$$
\left(1-\epsilon_{\mathrm{g}}\right) \rho_{\mathrm{g}} c_{\mathrm{g}} \frac{\partial T_{\mathrm{s}}}{\partial t}-\nabla \cdot\left[\left(1-\epsilon_{\mathrm{g}}\right) \lambda_{\mathrm{g}} \cdot \nabla T_{\mathrm{g}}\right]=H_{\mathrm{g}} \text { in } \Omega_{\mathrm{g}}
$$

with Cauchy type of $\mathrm{BC}$ :

$$
q_{n} T_{\mathrm{g}}=-\Phi_{\mathrm{gs}}\left(T_{\mathrm{s}}-T_{\mathrm{g}}\right)-\Phi_{\mathrm{fig}}\left(T_{\mathrm{i}}-T_{\mathrm{g}}\right) \text { on } \Gamma_{\mathrm{g}}
$$

In the heat exchange terms, $\Phi_{\text {fig }}, \Phi_{\mathrm{ff}}$, and $\Phi_{\mathrm{gs}}$ are thermal resistances between inflow and grout, inflow and outflow, and grout and soil parts. Detailed calculation of all heat exchange coefficients can be found in references of Diersch et al. (2011a) and Diersch (2013).

\section{Heat pump integration on the DBHE model and efficiency quantification}

When a DBHE is employed for heating purposes, the inflow temperature of the DBHE will be lower than the outflow temperature. In unit time, the amount of heat extracted from the DBHE can be quantified by the multiplication of refrigerant flow rate $Q_{\mathrm{r}}$, and the temperature difference between the inflow $T_{\mathrm{i}}$ and outflow $T_{\mathrm{o}}$ temperatures.

$$
\dot{Q}_{\mathrm{DBHE}}=\rho_{\mathrm{r}} c_{\mathrm{r}} Q_{\mathrm{r}}\left(T_{\mathrm{i}}-T_{\mathrm{o}}\right)
$$


In reality, the building thermal load does not equal to the load applied on the DBHE, since heat pumps are often installed to elevate the fluid temperature for the buildings. The performance of the heat pump is evaluated by the coefficient of performance (COP), which is defined as a ratio of the amount of thermal power supplied to the building $\dot{Q}_{\text {building }}$ and the amount of electricity consumed by the heat pump $W_{\mathrm{hp}}$.

$$
\mathrm{COP}=\frac{\dot{Q}_{\text {building }}}{W_{\mathrm{hp}}}
$$

As the building thermal load equals to the sum of DBHE thermal load and heat pump electricity consumption, the above equation can be reorganized.

$$
\dot{Q}_{\text {building }}=\frac{\mathrm{COP}}{\mathrm{COP}-1} \dot{Q}_{\mathrm{DBHE}}
$$

Although a number of factors have impact on the COP of heat pump, it is widely accepted (cf. Casasso and Sethi 2014; Kahraman and Çelebi 2009) that a linear relationship can be utilized to represent the dependency of COP on the outflow temperature of a DBHE.

$$
\mathrm{COP}=a T_{\mathrm{o}}+b
$$

Here $a$ and $b$ are constant variables under the specific operation model of heat pump. If nonlinear COP relationships are available, they can also be implemented in the numerical model. In this study, one COP curve has been provided based on a designed floor heating temperature of $35{ }^{\circ} \mathrm{C}$. The coefficients of Eq. 10 read $a=0.083, b=3.925$ for heating (cf. Hein et al. 2016a).

Different from the 1U-type BHE system, the DBHE has a considerably deeper borehole, i.e., higher hydraulic loss. Therefore, the electricity consumed by the circulating pump needs be quantified while evaluating the system performance. A coefficient of system performance (CSP) is proposed here to incorporate this effect, including both the electricity consumption from heat pump $W_{\mathrm{hp}}$ and from the circulating pump $W_{\mathrm{cp}}$. The CSP value is thus defined as

$$
\mathrm{CSP}=\frac{\dot{Q}_{\text {building }}}{W_{\mathrm{hp}}+W_{\mathrm{cp}}} .
$$

As mentioned by Holmberg et al. (2016), the electricity consumed by the circulating pump is mainly used to overcome pressure drop. Considering the flow rate of circulating fluid $Q_{\mathrm{r}}$, pressure drop $\Delta P$, and the efficiency of pump $\eta, W_{\mathrm{cp}}$ can be calculated as

$$
W_{\mathrm{cp}}=\frac{Q_{\mathrm{r}} \Delta P}{\eta} .
$$

Here $\eta$ is assumed to be $70 \%$. For the pressure drop both on the inner pipe and the annular space of a coaxial DBHE, it can be quantified as follows (Holmberg et al. 2016):

$$
\Delta P=\frac{L}{D_{\mathrm{h}}} \frac{\rho_{\mathrm{r}} v_{\mathrm{r}}^{2}}{2} \frac{1}{(0.790 \ln (R e)-1.64)^{2}},
$$


where $R e$ is the Reynolds number based on the hydraulic diameter in the annulus or inner pipe. $L$ denotes the length of the DBHE and $D_{\mathrm{h}}$ is the hydraulic diameter of pipes. $v_{r}$ is the flow velocity of the circulating fluid.

\section{Numerical models}

\section{Model setup}

In order to simulate accurate operating conditions of the DBHE-coupled heat pump system, a gradually increasing subsurface temperature distribution has to be specified in the initial conditions of the numerical model. In different modeling scenarios, dynamic flow rate of the circulating fluid in the pipe and various heat loads of the DBHE can also be imposed. In the first step, a homogeneous numerical model has been configured so that it can be verified against analytical solution. The detailed parameters of the system are shown in Table 1. Water was chosen as the circulation fluid in the DBHE. An initial calculation on the water density, viscosity, and heat capacity was performed with temperature and pressure values at the top and bottom of the DBHE, following the IAPWS formulation. It was found that the different thermal properties of water will only lead to a difference of $0.00103 \mathrm{~W} \mathrm{~m}^{-1} \mathrm{~K}^{-1}(0.9 \%)$ in the thermal resistance coefficient between inflow and outflow fluid. The resulting difference in grout thermal resistance is only $0.0004 \mathrm{~W} \mathrm{~m}^{-1} \mathrm{~K}^{-1}$, which changes only $1.8 \%$. Test numerical simulations confirm that the impact of varying thermophysical properties of circulating water can be safely neglected. Therefore, the properties of circulating water were assumed to be constant, and the values were chosen under condition at the DBHE top.

The entire domain adopted for the numerical model is $3 \mathrm{~km}$ in depth with a square cross section of $40,000 \mathrm{~m}^{2}$ as shown in Fig. 1 . The DBHE is $2.6 \mathrm{~km}$ long and located in the center of the domain, the top of DBHE is placed at $5 \mathrm{~m}$ beneath the surface. The $200 \times 200 \times 3000 \mathrm{~m}$ model domain was spatially discretized into 432,372 nodes and

Table 1 Parameters in the numerical model

\begin{tabular}{|c|c|c|c|}
\hline Parameter & Symbol & Value & Unit \\
\hline Borehole length & $L$ & 2600 & $\mathrm{~m}$ \\
\hline Borehole diameter & $2 r_{b}$ & 216 & $\mathrm{~mm}$ \\
\hline Diameter of inner pipe & $2 r_{i}$ & 110 & $\mathrm{~mm}$ \\
\hline Wall thickness of inner pipe & $t_{i}$ & 7.34 & $\mathrm{~mm}$ \\
\hline Diameter of outer pipe & $2 r_{\circ}$ & 178 & $\mathrm{~mm}$ \\
\hline Wall thickness of outer pipe & $t_{0}$ & 5.87 & $\mathrm{~mm}$ \\
\hline Thermal conductivity of inner pipe wall & $\lambda_{\mathrm{i}}$ & 0.21 & $\mathrm{~W} \mathrm{~m}^{-1} \mathrm{~K}^{-1}$ \\
\hline Thermal conductivity of outer pipe wall & $\lambda_{\circ}$ & 1.3 & $\mathrm{~W} \mathrm{~m}^{-1} \mathrm{~K}^{-1}$ \\
\hline Soil and rock thermal conductivity & $\lambda_{\mathrm{s}}$ & 2.5 & $\mathrm{~W} \mathrm{~m}^{-1} \mathrm{~K}^{-1}$ \\
\hline Heat capacity of soil/rock & $\rho_{\mathrm{S}} C_{\mathrm{S}}$ & $2.24 \times 10^{6}$ & $\mathrm{~J} \mathrm{~m}^{-3} \mathrm{~K}^{-1}$ \\
\hline Thermal conductivity of grout & $\lambda_{\mathrm{g}}$ & 1.3 & $W m^{-1} K^{-1}$ \\
\hline Heat capacity of grout & $\rho_{\mathrm{g}} C_{\mathrm{g}}$ & $3.8 \times 10^{6}$ & $\mathrm{~J} \mathrm{~m}^{-3} \mathrm{~K}^{-1}$ \\
\hline Thermal conductivity of circulating fluid & $\lambda_{r}$ & 0.59 & $\mathrm{~W} \mathrm{~m}^{-1} \mathrm{~K}^{-1}$ \\
\hline Heat capacity of circulating fluid & $\rho_{\mathrm{r}} c_{\mathrm{r}}$ & $4.19 \times 10^{6}$ & $\mathrm{~J} \mathrm{~m}^{-3} \mathrm{~K}^{-1}$ \\
\hline Viscosity of circulating fluid & $\mu_{\mathrm{r}}$ & $1.14 \times 10^{-3}$ & $\mathrm{~kg} \mathrm{~m}^{-1} \mathrm{~s}^{-1}$ \\
\hline Flow rate of circulating fluid & $Q_{\mathrm{r}}$ & $8.33 \times 10^{-3}$ & $\mathrm{~m}^{3} \mathrm{~s}^{-1}$ \\
\hline
\end{tabular}


810,380 elements to accommodate the $2600 \mathrm{~m}$ deep borehole (Fig. 1). There are 2700 line elements representing the DBHE and 807,680 triangular prism elements for the soil compartment. Diersch et al. (2011b) pointed out that the mesh density in the vicinity of the DBHE can affect the amount of heat transfer between DBHE and surrounding soil. Hence, the distance between the DBHE node and surrounding soil nodes were refined according to the borehole radius and the number of surrounding soil nodes. In this mesh, there are six surrounding soil nodes around the DBHE. Thus, the optimal node distance is set to be $0.66204 \mathrm{~m}$ with the borehole radius of $0.108 \mathrm{~m}$, following the suggestions by Diersch et al. (2011b).

\section{Model verification}

The numerical result was compared against analytical solution in order to verify its correctness. Simulated soil temperature distribution indicates that the DBHE operation can reach around $100 \mathrm{~m}$ away after an simulated operation of 30 years. The geometric model ensures that there is no interference caused by the boundary effect. The analytical solution employed for verification here was proposed by Beier et al. (2014). The comparison of numerical and analytical solution is presented in Fig. 2, where the inflow and outflow temperature from the DBHE was compared. It can be found that two results fit very well over the period of one heating season. The largest relative error is only around $2.3 \%$, meaning there is temperature difference of less than $0.7{ }^{\circ} \mathrm{C}$ after operation for 103 days. Among the various analytical solutions that can model the DBHE operation ( $\mathrm{Li}$ and Lai 2015), Beier's solution was applied in this work to compare with numerical results because it is a transient heat transfer model that explicitly simulates the temperatures on inner and annulus pipes, instead of only calculating the mean temperature approximation in the borehole. In the analytical and numerical models, the calculated thermal resistances between the pipe and the soil parts have minor differences, leading to the deviation observable in the inflow and outflow temperature profile.

As shown in Fig. 2, such temperature differences will barely have any significant influence on the system performance, both in short- or long-term analysis. It has to be

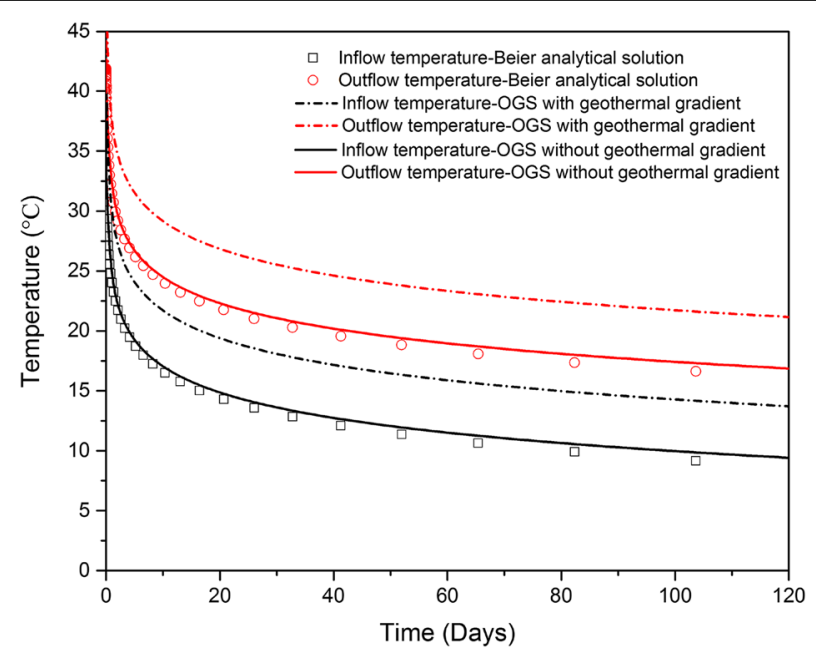

Fig. 2 Numerical model verification against analytical solution over one heating season (120 days) 
mentioned here that the initial geothermal temperature was considered to be homogeneous, so that the analytical solution can be calculated. This deviation from the reality will lead to a lower evaluation on the DBHE's performance. With the geothermal gradient applied on the initial condition, the outflow temperature will increase by $4.29^{\circ} \mathrm{C}$ after 120 days as predicted by the numerical model, which is much higher than the deviation mentioned above. As Fig. 2 demonstrates the temperature variation of inflow and outflow pipe over time, Fig. 3 depicts the temperature distribution over depth. Here, the vertical temperature distribution of the circulating fluid in DBHE fits the analytical solution very well. The largest relative error is $2.4 \%$, which occurs after operation for 1 day. The maximum temperature difference between Beier's solution and OGS numerical results is $0.9{ }^{\circ} \mathrm{C}$. As operational time increases, the deviation will be much smaller. The reason behind this phenomenon is that at the beginning of the simulation, temperature of circulation fluid is largely controlled by the thermal resistance between the pipe and the soil. While the heat extraction continues, thermal conductivity of the surrounding soil gradually becomes the more dominating factor. Therefore, the difference in governing equations is having less impact on the predicted temperature values. Based on the above comparison, the numerical model here is successfully verified and can be applied for the analysis of DBHE system performance.

\section{Simulated scenarios}

With the verified numerical model, different scenarios were established and simulated. The overview of these scenarios is listed in Table 2. In Fig. 3, the initial soil temperature was considered to be constant and homogeneous for comparison against analytical solution. This assumption is far from reality as it is well known that the soil temperature will gradually increase with depth. Therefore, the modeling scenario \#0 was prepared to reflect the natural geothermal gradient. After that, scenario \#1A-D was designed with different values of pipe wall thermal conductivity. First, two types of materials were chosen for the outer pipe, one was made of steel and the other of concrete. Depending on

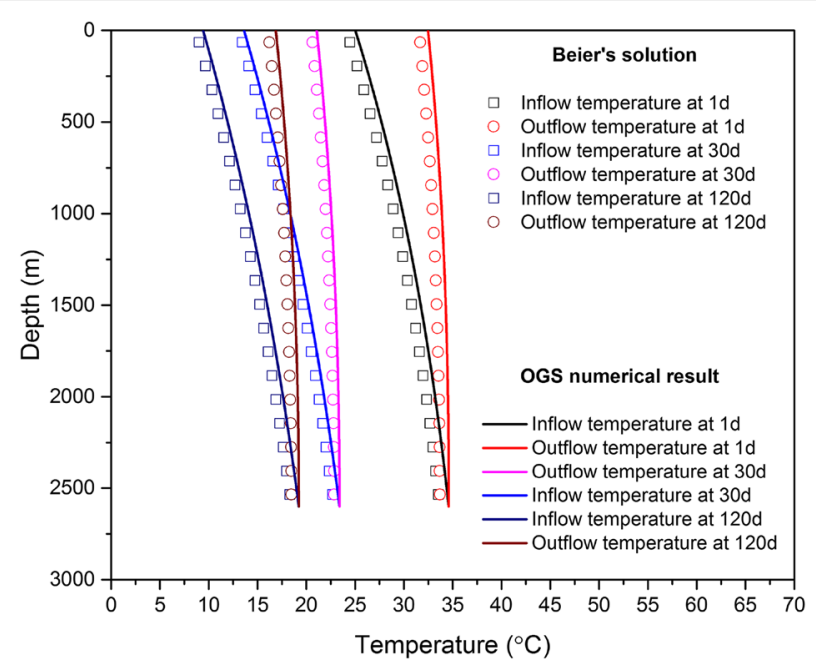

Fig. 3 Comparison of temperature distribution with analytical solution in one heating season 
Table 2 List of all simulated scenarios and features

\begin{tabular}{|c|c|c|c|c|c|c|}
\hline Scenario ID & $\begin{array}{l}\text { Geothermal } \\
\text { gradient }\left({ }^{\circ} \mathrm{C}\right. \\
\left.\mathrm{m}^{-1}\right)\end{array}$ & $\begin{array}{l}\text { Pipe wall } \\
\text { thermal } \\
\text { conductivity } \\
\left(\mathrm{W} \mathrm{m}^{-1} \mathrm{~K}^{-1}\right)\end{array}$ & $\begin{array}{l}\text { Grout } \\
\text { thermal } \\
\text { conductivity } \\
\left(\mathrm{W} \mathrm{m}^{-1} \mathrm{~K}^{-1}\right)\end{array}$ & $\begin{array}{l}\text { Soil thermal } \\
\text { conductivity } \\
\left(\mathrm{W} \mathrm{m}^{-1} \mathrm{~K}^{-1}\right)\end{array}$ & $\begin{array}{l}\text { Operation } \\
\text { period (days) }\end{array}$ & $\begin{array}{l}\text { Groundwater } \\
\text { flow }\end{array}$ \\
\hline 0 & 0.03 & Const. & 1.3 & 2.5 & 120 & $\mathrm{~N}$ \\
\hline $1 A-D$ & 0.03 & Var. & 1.3 & 2.5 & 120 & $\mathrm{~N}$ \\
\hline $2 A-D$ & 0.03 & Const. & Var. & 2.5 & 120 & $N$ \\
\hline $3 A-D$ & Var. & Const. & 1.3 & 2.5 & 120 & $\mathrm{~N}$ \\
\hline $4 A-E$ & 0.03 & Const. & 1.3 & Var. & 120 & N \\
\hline $5 A-D$ & 0.03 & Const. & 1.3 & 2.5 & 120 & Y \\
\hline $6 A-B$ & 0.03 & Const. & 1.3 & 2.5 & $\begin{array}{l}10950(30 \\
\text { years) }\end{array}$ & $\mathrm{N}$ \\
\hline
\end{tabular}

whether an insulation layer was added, four different thermal conductivity values can be derived (\#1A-D). Details on these conductivity values are listed in Table 3. Desmedt et al. (2012) and Zhang et al. (2015) declared that the application of thermally enhanced grout will improve the performance of the BHE. For the DBHE system, considering the large quantity of grout required to seal a deep borehole, the additionally initial investment needs to be justified by the long-term gain in performance. Also in reality, some companies may choose to skip sealing DBHE outer pipe, or just doing it partially to cut the cost. Therefore, four different values of grout thermal conductivity were simulated including sealing the outer pipe with concrete $(\# 2 C)$, with thermally enhanced grout (\#2D), leaving it unfilled (\#2A), or filled partially with water (\#2B, see Table 4 for details).

Since the sensible heat stored in soil is the main energy source for DBHE system, sensitivity analysis regarding the soil properties is also investigated here. As the geothermal gradient can vary in different places, the initial soil temperature distribution and heat flux into the domain can be different. Based on the ideal geological conditions, four scenarios were designed (\#3A-D) with the geothermal gradient increasing from 0.03 to $0.04{ }^{\circ} \mathrm{C} \mathrm{m}^{-1}$ (see details in Table 5) along with increasing thermal extraction rates. Then five scenarios were simulated (\#4A-E) with different soil thermal conductivity values listed in Table 6. In order to investigate impact of groundwater flow on the performance of the DBHE system, four scenarios (\#5A-D) were designed with a 13-m-thick aquifer positioned at three different depths $(\# 5 \mathrm{~A}-\mathrm{C})$. And there are another five aquifers with

Table 3 Different outer pipe materials with different inner pipes

\begin{tabular}{|c|c|c|c|}
\hline Scenario ID & $\begin{array}{l}\text { Inner pipe wall thermal } \\
\text { conductivity }\left(\mathrm{W} \mathrm{m}^{-1}\right. \\
\left.\mathrm{K}^{-1}\right)\end{array}$ & $\begin{array}{l}\text { Outer pipe wall thermal } \\
\text { conductivity }\left(\mathrm{W} \mathrm{m}^{-1}\right. \\
\left.\mathrm{K}^{-1}\right)\end{array}$ & Description \\
\hline $1 \mathrm{~A}$ & 0.5 & 1.3 & $\begin{array}{l}\text { Concrete outer pipe without heat insula- } \\
\text { tion layer on the inner pipe }\end{array}$ \\
\hline $1 \mathrm{~B}$ & 0.1 & 1.3 & $\begin{array}{l}\text { Concrete outer pipe with heat insulation } \\
\text { layer on the inner pipe }\end{array}$ \\
\hline $1 \mathrm{C}$ & 0.5 & 20 & $\begin{array}{l}\text { Steel outer pipe without heat insulation } \\
\text { layer on the inner pipe }\end{array}$ \\
\hline $1 \mathrm{D}$ & 0.1 & 20 & $\begin{array}{l}\text { Steel outer pipe with heat insulation layer } \\
\text { on the inner pipe }\end{array}$ \\
\hline
\end{tabular}


Table 4 Parameter values used in the model to represent different grout materials

\begin{tabular}{lll}
\hline Scenario ID & $\begin{array}{l}\text { Grout thermal conductivity } \\
\left(\mathbf{W} \mathbf{~ m}^{-\mathbf{1}} \mathbf{K}^{\mathbf{- 1}} \mathbf{)}\right.\end{array}$ & Description \\
\hline 2A & 0.35 & Gap filled with half air and half water \\
2B & 0.68 & Gap fully saturated with water \\
2C & 1.3 & Filled with concrete \\
2D & 2.1 & Thermally enhanced material as grout \\
\hline
\end{tabular}

Table 5 Variation of geothermal gradient with different specific heat extraction rates

\begin{tabular}{|c|c|c|c|}
\hline Scenario ID & $\begin{array}{l}\text { Geothermal } \\
\text { gradient }\left({ }^{\circ} \mathrm{C} \mathrm{m}^{-1}\right)\end{array}$ & $\begin{array}{l}\text { Specific heat extraction rate } \\
\text { imposed on the DBHE }\left(\mathrm{W} \mathrm{m}^{-1}\right)\end{array}$ & Description \\
\hline $3 \mathrm{~A}$ & 0.03 & 100 & Standard geothermal gradient \\
\hline $3 B$ & 0.04 & 100 & Elevated geothermal gradient \\
\hline $3 C$ & 0.04 & 200 & Elevated geothermal gradient \\
\hline $3 \mathrm{D}$ & 0.04 & Var. & Elevated geothermal gradient \\
\hline
\end{tabular}

Table 6 Variation of soil thermal conductivity

\begin{tabular}{lll}
\hline Scenario ID & $\begin{array}{l}\text { Soil thermal conductivity } \\
\left(\mathbf{W ~ m}^{-\mathbf{1}} \mathbf{K}^{-\mathbf{1}}\right)\end{array}$ & $\begin{array}{l}\text { Heat load on the DBHE } \\
\text { system (kW) }\end{array}$ \\
\hline $4 \mathrm{~A}$ & 2.0 & 390 \\
$4 \mathrm{~B}$ & 2.25 & 390 \\
$4 \mathrm{C}$ & 2.5 & 390 \\
$4 \mathrm{D}$ & 2.75 & 390 \\
$4 \mathrm{E}$ & 3.0 & 390 \\
\hline
\end{tabular}

the thickness of $12 \mathrm{~m}$ each further added in upper part of the soil so that the influence of multi-layer aquifers on the system can also be quantified (\#5D). The intention here is to systematically reveal how the DBHE system performance changes if the subsurface condition is favorable. To investigate the long-term performance of the DBHE system, scenarios \#6A-B were simulated for a period of 30 years long. Preliminary test simulation showed that the fluctuating ground surface temperature has barely any influence on the simulated inflow and outflow temperatures. Therefore, the surface temperature was assumed to be constant in all the modeling scenarios.

\section{Results and discussion}

\section{Temperature distribution inside the DBHE}

In scenario \#0, the simulated result of vertical temperature distribution at different operational times is depicted in Fig. 4. It can be found that the circulating fluid temperature quickly drops after the start of operation. This trend will stabilize itself as the surrounding soil temperature reaches equilibrium with the circulating fluid. When compared with the result without geothermal gradient in Fig. 3, the slope of the inflow temperature increases only slightly within the first $800 \mathrm{~m}$, and this slope is significantly steeper at the 


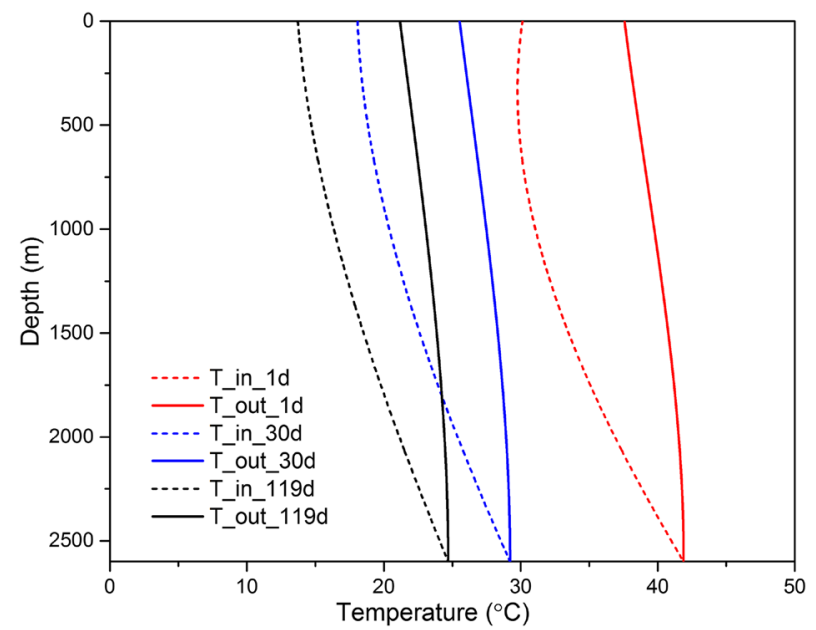

Fig. 4 Vertical temperature distribution of circulating fluid with geothermal gradient

depth greater than $800 \mathrm{~m}$. That reveals that due to the presence of the geothermal gradient, heat extraction is more efficient in the lower part of the DBHE. Since the ground surface temperature is ca. $6{ }^{\circ} \mathrm{C}$ and the geothermal gradient is configured to be $0.03{ }^{\circ} \mathrm{C}$ $\mathrm{m}^{-1}$, the subsurface temperature reaches $30^{\circ} \mathrm{C}$ at the depth of $800 \mathrm{~m}$. At depth greater than $800 \mathrm{~m}$, the surrounding soil starts to be hotter than the circulating fluid, leading to a higher heat flux from the surrounding soil into the DBHE.

As explained above, the sensible heat is mainly extracted from the deeper part of the soil, and the DBHE will lose some heat to the surrounding soil when the fluid is pumped upwards. As the operation proceeds, the temperature of upper soil will be gradually heated up. This means, the equilibrium depth originally located at $800 \mathrm{~m}$ depth will also be gradually shifted upwards. This feature is unique in the DBHE and cannot be found in shallow single-U or double-U-type of BHEs. As shown in Fig. 4, the inner outflow fluid temperature keeps decreasing from the bottom to the top. This indicates that the heat loss from inner to outer pipe exists throughout the entire DBHE. This also suggests that, if the inner pipe wall can be better insulated (with a lower thermal conductivity), the amount of heat loss will be constrained and the efficiency of the DBHE can be improved.

\section{Heat flux analysis}

Based on the simulated temperature presented in the above section, it can be further analyzed to reflect the heat flux distribution between different components in the borehole at any time. Over a heating season (from 1 to 119 day), there is a clear trend that can be found in Fig. 5. The blue line, which represents the heat flux from grout to soil, will intersect with the purple line, that refers to the flux from grout to outer pipe. This interaction point is located at a depth of $800 \mathrm{~m}$ at 1 day, and will be gradually shifted upwards to ca. $200 \mathrm{~m}$ after 119 days. Physically, this interaction point indicates the location where the heat flux flow into and out of the grout zone equals to zero. This also means that, for the section above this point, DBHE is losing energy to the surrounding soil, while only the section below this point is contributing to the extraction of geothermal energy. 

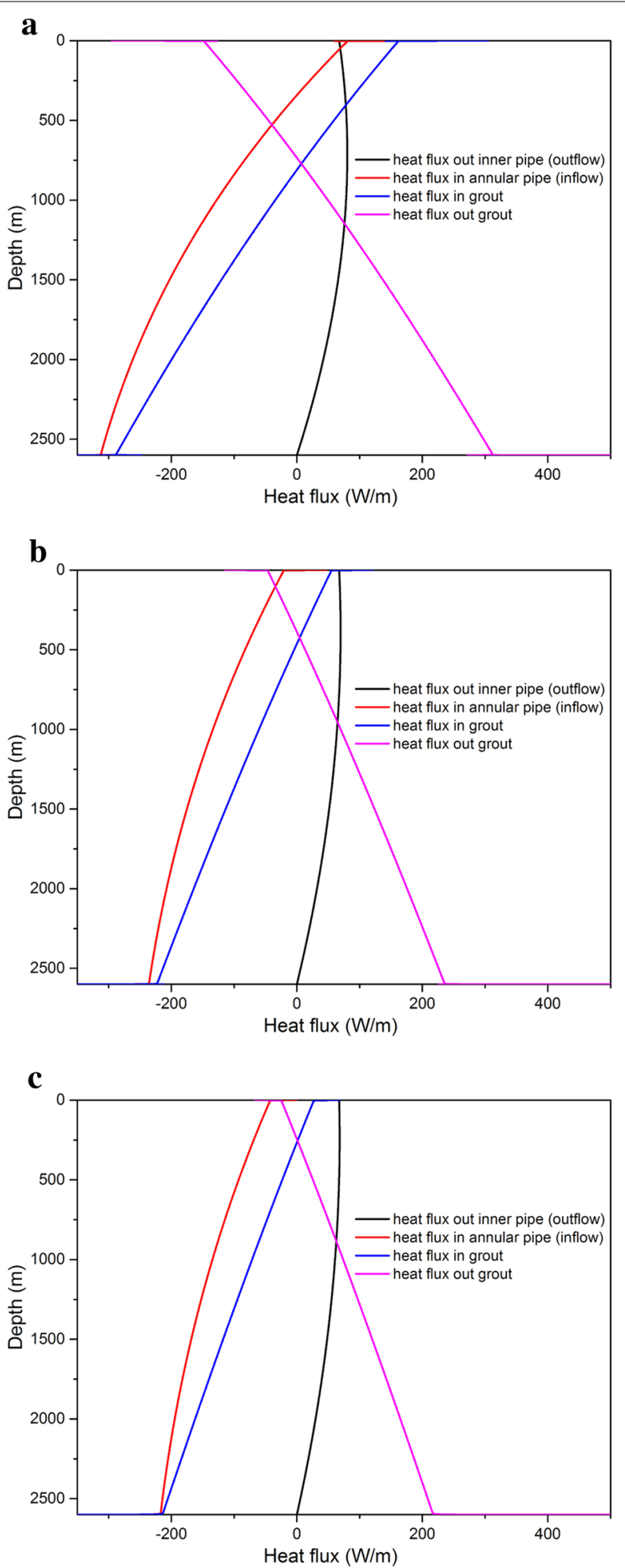

Fig. 5 Heat flux distribution over the entire DBHE depth after operation of $\mathbf{a} 1$ day, $\mathbf{b} 30$ days, and $\mathbf{c} 119$ days 
The same process is also indicated in the change of the red line, representing the heat flux going in the annular pipe. There, the value difference between bottom and top of the DBHE will decrease over time. Considering the upper part of soil is heated due to heat loss from the DBHE, the heat flux going into the annular pipe is positive at 1 day. After the operation of 30 days, the same heat flux turns into negative values at the top of the DBHE, suggesting that the ground surface temperature is higher than the inflow temperature and the sensible heat in the subsurface is being extracted, and this process is not restricted just to the bottom part. When looking into the black line, which indicates the heat loss from the inner pipe, it can be found that this loss does not change much over time. The absolute amount of heat loss is zero at the bottom of the DBHE, as there is no temperature difference between the inner and annulus pipe, while it increases itself and reaches the maximum near the ground surface. This implies that when applying insulation material to cut this heat loss, the material should be applied throughout the entire depth of the inner pipe, not only the upper part.

It is noticed that the heat flux analysis can also be used to check the balance and accuracy of the numerical model. At a particular time step, the simulated heat flux between the soil and the grout can be integrated over the entire depth of DBHE. The calculated value was compared to the heat extraction rates imposed on the DBHE at that moment. It was found that these values fit well with each other, bearing only a relative deviation of $0.03 \%$. This is more proof that the numerical model is delivering accurate results throughout the entire simulated heating period.

\section{Influence of different pipe materials}

The impact of different pipe materials is mainly investigated by varying the pipe wall thermal conductivity values in the numerical model (as listed in Table 3). From scenario \#1A to \#1D, the outflow temperature of the DBHE and its evolution trend is predicted by the numerical simulation, and the statistical distribution of heat pump COP was then calculated accordingly following Eq. 10. Such distribution over an entire heating season is summarized in Fig. 6. By comparing the result of scenario \#1A and scenario \#1B, it can be revealed that the heat pump COP will be improved by approx. $7.2 \%$ when applying the material with lower thermal conductivity on the inner pipe. On the contrary, if the outer pipe concrete material (scenario \#1B) is substituted by steel (scenario \#1D), the average COP value can only be improved by $1.57 \%$. It can be concluded that although both insulating the inner pipe and enhancing the outer pipe thermal conductivity will improve the system performance, the outer pipe wall has a relatively minor impact. In real projects, installing the concrete outer pipe instead of steel will save a lot of initial investment, as the DBHE is typically 2 to $3 \mathrm{~km}$ long. Therefore, it is economically more attractive to use low thermally conductive material (such as high-density polyethyleneHDPE) as the inner pipe.

\section{Influence of grout thermal conductivity}

As listed in Table 1, the grout thickness is $19 \mathrm{~mm}$. The corresponding grout thermal conductivity varies from 0.35 to $2.1 \mathrm{~W} \mathrm{~m}^{-1} \mathrm{~K}^{-1}$ (listed in Table 4). Numerical results presented in Fig. 7 show that the outflow temperature of the DBHE increases $12.61{ }^{\circ} \mathrm{C}$ over a typical heating season, when the grout thermal conductivity increased from 0.35 


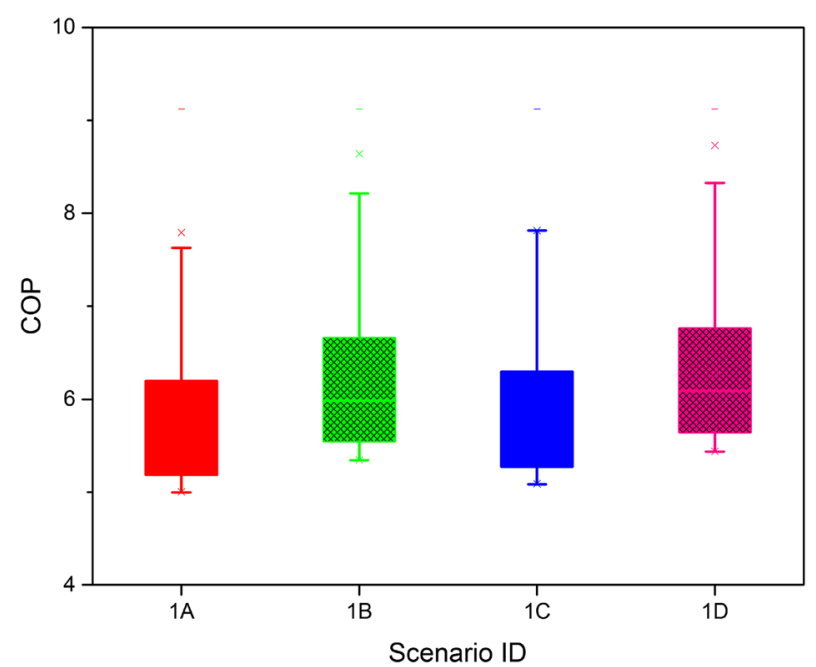

Fig. 6 Statistic distribution of heat pump COP with different pipe materials

(scenario \#2A) to $2.1 \mathrm{~W} \mathrm{~m}^{-1} \mathrm{~K}^{-1}$ (scenario \#2D) and the average COP of coupled heat pump will increase by 1.05 . The average COP (cf. Fig. 7b) will be improved by $9.88 \%$ if the thermally enhanced material (scenario \#2D) is used as grout instead of concrete (scenario $\# 2 \mathrm{C}$ ) and the outflow temperature will increase by $6.24^{\circ} \mathrm{C}$ at the end of the season. This analysis indicates that thermally enhanced grout material can significantly improve the heat transfer between the borehole wall and the outer pipe, thus leading to a highersystem performance. Scenarios \#2A and \#2B represent the cases where the DBHE is not properly sealed. For $\# 2 \mathrm{~A}$, it is assumed that the gap between the DBHE and the surrounding soil is filled by half water and half air. Scenario \#2B refers to those boreholes fully filled with water. As shown in Fig. 7, in these two scenarios, the outflow temperature in \#2B will be $4.15^{\circ} \mathrm{C}$ higher, and the corresponding COP will also be improved by $7.3 \%$. It can be concluded that the system performance will greatly deteriorate if the gap between borehole wall and surrounding soil is not properly sealed.

\section{Influence of geothermal gradient}

In the simulated scenarios, the large portion of extracted geothermal energy is coming from the sensible heat stored in the surrounding soil. Therefore, the initial soil temperature distribution can be reflected in the average geothermal gradient. To achieve this, steady-state heat transport simulations were conducted with the amount of heat flux imposed at the bottom of the model domain that correspond to the $0.03{ }^{\circ} \mathrm{C} \mathrm{m}^{-1}$ and $0.04{ }^{\circ} \mathrm{C} \mathrm{m}^{-1}$ geothermal gradient. These simulations produced two different linear distributions of soil temperature over the entire depth, which shows the equilibrium state of an undisturbed subsurface. These two distributions are then applied in scenarios \#3A to \#3D as initial condition for the soil temperature.

With the initial soil temperature fixed, scenarios \#3A to \#3D (cf. Table 5) were simulated to investigate the impact of different geothermal gradients. The numerical results are presented and compared in Fig. 8. Fig. 8a shows that the outflow temperature of the DBHE increases by $13.41{ }^{\circ} \mathrm{C}$ when the geothermal gradient is elevated from 0.03 to 

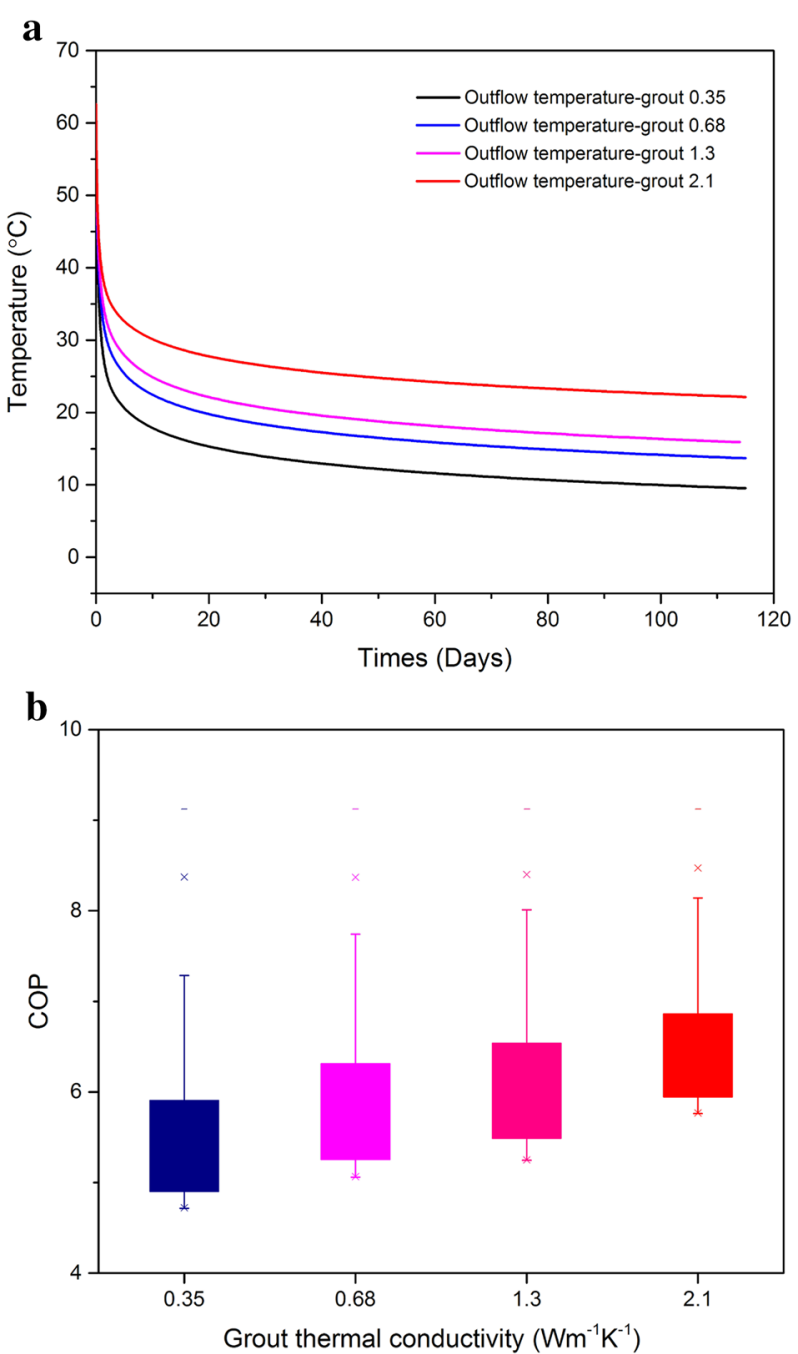

Fig. 7 Influence of different grout thermal conductivity values on $\mathbf{a}$ the temperature of DBHE and $\mathbf{b}$ COP statistic distribution of heat pump in one heating season

$0.04{ }^{\circ} \mathrm{C} \mathrm{m}^{-1}$, with the specific heat extraction rate kept the same at $100 \mathrm{~W} \mathrm{~m}^{-1}$. This suggests that a higher heat extraction rate can be applied to the same system when a higher geothermal gradient is present. Following this thought, the extraction rate was increased to $200 \mathrm{~W} \mathrm{~m}^{-1}$ (scenario \#3C). It can be found that in this case that the inflow temperature is quickly dropping and it will approach $0{ }^{\circ} \mathrm{C}$ after only about 50 days. In reality, this means the DBHE is heavily overloaded and heat pump system is very likely to automatically shut down.

To find out the maximum sustainable heat load of the DBHE under the geothermal gradient of $0.04{ }^{\circ} \mathrm{C} \mathrm{m}^{-1}$, the imposed thermal load was then adjusted as shown in Fig. $8 \mathrm{~b}$ according to the trend of energy demand during winter. The average specific heat extraction rate in one heating season is $157.3 \mathrm{~W} \mathrm{~m}^{-1}$. Under this condition, the lowest outflow temperature is $16.32{ }^{\circ} \mathrm{C}$ and the final outflow temperature is $30.09{ }^{\circ} \mathrm{C}$ at the end of one heating season. As shown in Fig. 8b, the lowest inflow temperature is approaching 

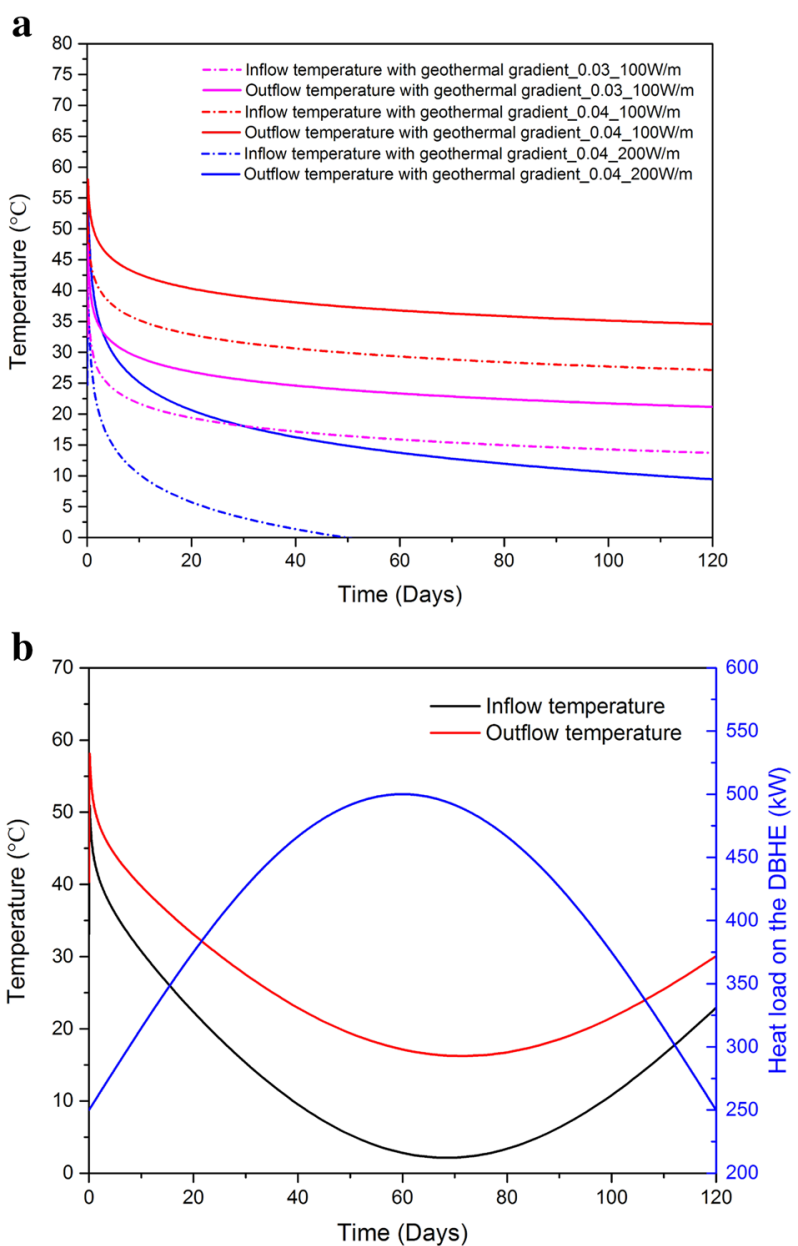

Fig. 8 Influence of geological condition on the DBHE performance. a The numerical results of scenarios \#3A to $C ; \mathbf{b}$ Various heat load on the DBHE and numerical results of inflow and outflow temperature (scenario \#3D)

$2{ }^{\circ} \mathrm{C}$ when the instantaneous heat load reaches $500 \mathrm{~kW}\left(192.3 \mathrm{~W} \mathrm{~m}^{-1}\right)$. Combined with numerical results of scenario \#3C, it can be concluded that the sustainable specific heat extraction rate can be enlarged bigger than $150 \mathrm{~W} \mathrm{~m}^{-1}$ but smaller than $200 \mathrm{~W} \mathrm{~m}^{-1}$.

\section{Influence of soil thermal conductivity}

As shown in the previous section, the geothermal gradient regulates the initial soil temperature over depth, thus further determining the amount of sensible heat available for extraction. On the other hand, the amount of extractable heat within a unit time period is also controlled by the soil thermal conductivity. With this assumption in mind, five scenarios were designed with various soil thermal conductivity values to investigate its influence (see Table 6). As shown in Fig. 9, when the soil thermal conductivity increases from $2.0 \mathrm{~W} \mathrm{~m}^{-1} \mathrm{~K}^{-1}$ (scenario \#4A) to $3.0 \mathrm{~W} \mathrm{~m}^{-1} \mathrm{~K}^{-1}$ (scenario \#4E), the outflow temperature of the DBHE will be elevated by $9.45^{\circ} \mathrm{C}$, accounting for 


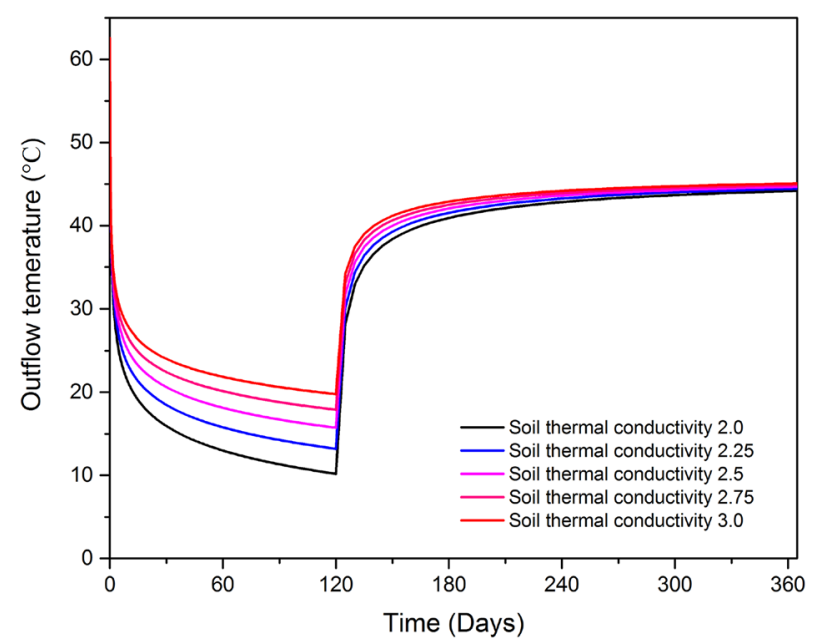

Fig. 9 Influence of soil thermal conductivity on the outflow temperature of DBHE

Table 7 Groundwater flow in the subsurface

\begin{tabular}{llll}
\hline Scenario ID & Aquifer number & Aquifer thickness $(\mathbf{m})$ & Aquifer location \\
\hline $5 \mathrm{~A}$ & 1 & 13 & $395 \mathrm{~m}$ \\
$5 \mathrm{~B}$ & 1 & 13 & $1395 \mathrm{~m}$ \\
$5 \mathrm{C}$ & 1 & 13 & $2395 \mathrm{~m}$ \\
$5 \mathrm{D}$ & 6 & $12 * 5$ and $13 * 1$ & Distributed every \\
& & $50 \mathrm{~m}$ based \\
& & on 5B \\
\hline
\end{tabular}

a $15 \%$ increase. It is also noticed that the marginal performance gain from increasing soil thermal conductivity is gradually decreasing. For example, when the soil thermal conductivity is increased from $2.0 \mathrm{~W} \mathrm{~m}{ }^{-1} \mathrm{~K}^{-1}$ (scenario \#4A) to $2.25 \mathrm{~W} \mathrm{~m}^{-1} \mathrm{~K}^{-1}$ (scenario \#4B), the outflow temperature will increase by $2.97{ }^{\circ} \mathrm{C}$. When the conductivity is further increased from $2.75 \mathrm{~W} \mathrm{~m}^{-1} \mathrm{~K}^{-1}$ (scenario \#4D) to $3.0 \mathrm{~W} \mathrm{~m}^{-1} \mathrm{~K}^{-1}$ (scenario $\# 4 \mathrm{E}$ ), the elevation is only $1.57^{\circ} \mathrm{C}$. Fig. 9 also reveals that a higher thermal conductivity value will lead to a faster recovery in the outflow temperature. By comparing the soil thermal conductivity of $2.0 \mathrm{~W} \mathrm{~m}^{-1} \mathrm{~K}^{-1}$ (scenario \#4A) and $3.0 \mathrm{~W} \mathrm{~m}^{-1} \mathrm{~K}^{-1}$ (scenario \#4E), there will be an outflow temperature difference of $0.89^{\circ} \mathrm{C}$ at the end of the recovery period. Although it looks insignificant, such difference in outflow temperature will be accumulated over decades of operation. This means that with the low soil thermal conductivity, the inflow temperature of the DBHE is likely to approach $0{ }^{\circ} \mathrm{C}$ much earlier than in the high conductivity case.

\section{Influence of groundwater flow}

It is well known that groundwater flow will greatly enhance the performance of shallow BHEs. For the DBHE system, groundwater containing aquifers are not likely to cover the entire length of the borehole. It is more likely that aquifers with high permeability are intersecting the DBHE at various depths. To reflect this reality, a total of four scenarios were designed as listed in Table 7. In scenarios \#5A to \#5C, an aquifer with 

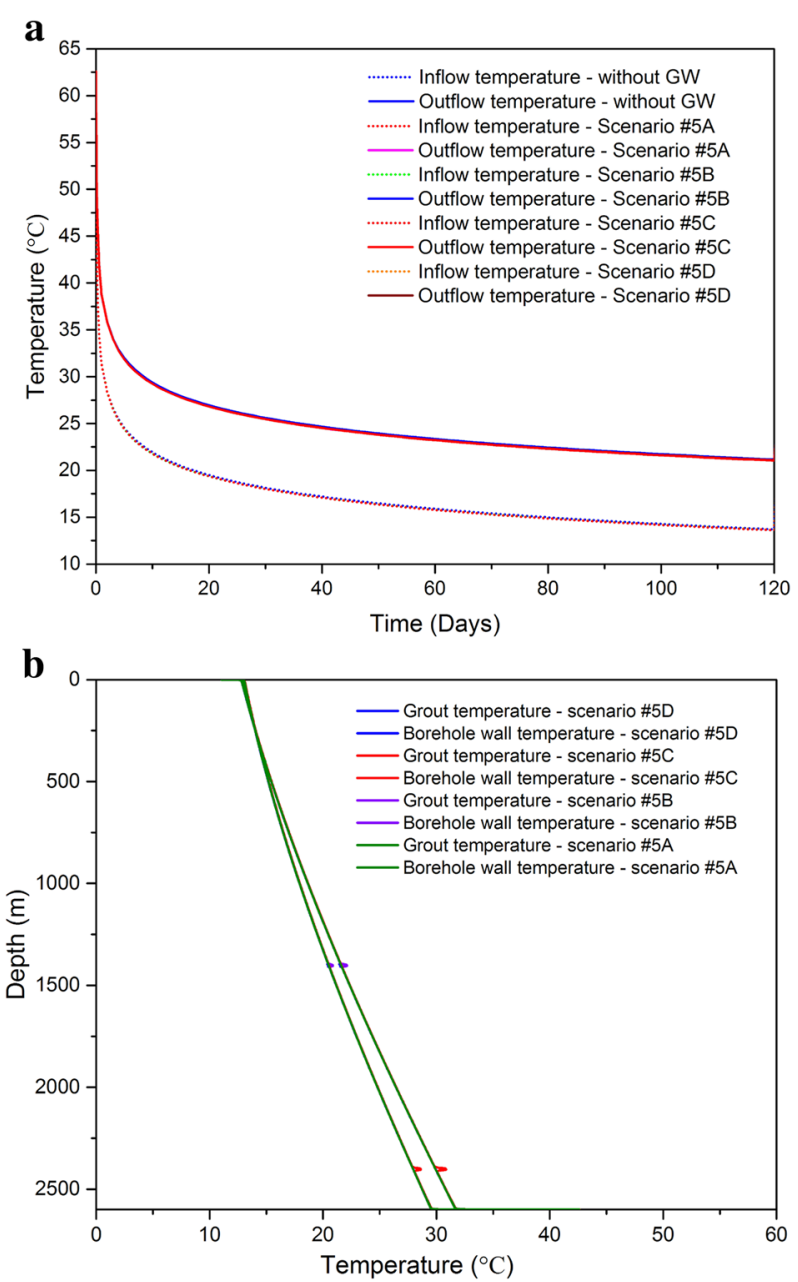

Fig. 10 Influence of groundwater flow on the $\mathbf{a}$ inflow/outflow temperature evolution and $\mathbf{b}$ temperature distribution at the end of one heating season

$13 \mathrm{~m}$ thickness was assumed to be located at different depths, and there is a horizontal groundwater flow with a Darcy velocity of $0.368 \mathrm{~m} \mathrm{day}^{-1}$ in the aquifer. In scenario \#5D, five aquifers with the thickness of $12 \mathrm{~m}$ were further added, with a 50- $\mathrm{m}$ interval between the depth of $50 \mathrm{~m}$ down to $360 \mathrm{~m}$, mimicking the very porous and fully saturated shallow sediments. The Darcy velocity in these aquifers was assumed to be of the same value, which translates to about $130 \mathrm{~m} \mathrm{year}^{-1}$ of horizontal groundwater movement. These scenarios were designed to reveal, whether the groundwater in single or multiple aquifers will increase the sustainable heat extraction rate of the DBHE.

The simulated numerical results presented in Fig. 10 indicate that the groundwater movement has only very minor influence on the DBHE performance. The outflow temperature at the end of one heating season remains almost the same in all four scenarios regardless of the number or locations of aquifers. In scenario \#5D, where a total of six aquifers were added, the outflow temperature at the end of the heating season is only $0.1^{\circ} \mathrm{C}$ less than that the baseline case where no groundwater flow was considered. In this 
case, the groundwater flow in shallow aquifers is actually increasing the heat loss of the DBHE.

The temperature peaks in Fig. 10b at a depth of $2395 \mathrm{~m}$ is a clear indication of deep aquifers' influence (scenario \#5C). In comparison to other scenarios, the extracted thermal energy via the DBHE is mainly from the bottom part of the soil, as already demonstrated by the heat flux analysis. Deep aquifers have higher temperature and provide extra thermal energy through the groundwater advection process. But heat energy supplied by deep aquifers only accounts for a tiny ratio of total amount of extracted energy. And such extra energy supplied by deep aquifers will be distributed along the depth of the DBHE during the circulating fluid flowing process so that the outflow temperature of the DBHE will not be changed much. All in all, since the overall depth of the aquifer in the investigated scenarios is still a small portion of the DBHE length, the amount of thermal energy recharged (deep aquifers) or discharged (shallow aquifers) through the groundwater advection takes only a small part in the overall extracted heat from the deep subsurface. This feature is largely due to the extended length of the DBHE, which is different from shallow BHEs.

It should be noted that the average soil thermal conductivity will be affected due to the presence of aquifers in the subsurface. When the porous media is fully saturated or partially saturated with water, the air in pores will be substituted and the average soil thermal conductivity will increase so that the system performance will be improved as discussed before.

\section{Long-term sustainability analysis}

As the DBHE system is constructed for building heating purposes, it has to be running for a long period of time (e.g., 30 years) in order to cover its high initial investment. In the long term, the system is actually constrained by the lowest temperature of the circulating fluid that enters and leaves the heat pump. Based on communication with the equipment vendors, it is learned that the minimum outflow temperature of the DBHE has to be kept higher than $4{ }^{\circ} \mathrm{C}$, and the inflow temperature should be above the freezing point, so that unfavorable freezing and thawing processes can be avoided around the DBHE. With such criteria in mind, the numerical models were simulated with a range of different thermal loads on the DBHE, ranging from $50 \mathrm{~W} \mathrm{~m}^{-1}$ up to $200 \mathrm{~W} \mathrm{~m}^{-1}$ of specific heat extraction rate. In these long-term simulations, the domain size was carefully checked to guarantee that there are no interactions between the thermal plume and the lateral boundaries of the domain.

The 30-year long-term numerical results of $100 \mathrm{~W} \mathrm{~m}^{-1}$ and $125 \mathrm{~W} \mathrm{~m}^{-1}$ are presented in Fig. 11 for comparison. It can be found that, over a 30-year-long period with $100 \mathrm{~W}$ $\mathrm{m}^{-1}$ specific extraction rate, both inflow and outflow temperatures at the beginning of the heating season will drop a few degrees in the first couple of years. The size of this temperature drop will gradually decrease over time. Looking at the first 20 years, the initial outflow temperature decreased by $4.2{ }^{\circ} \mathrm{C}$ in comparison to the equilibrium initial temperature. For the operation time beyond 20 years, the temperature profile barely changes, therefore it can be regarded to have reached the quasi steady-state. The stabilized outflow temperature profile suggests that the heat extraction and recovery in the subsurface has reached equilibrium. In this case, the minimum outflow temperature can 


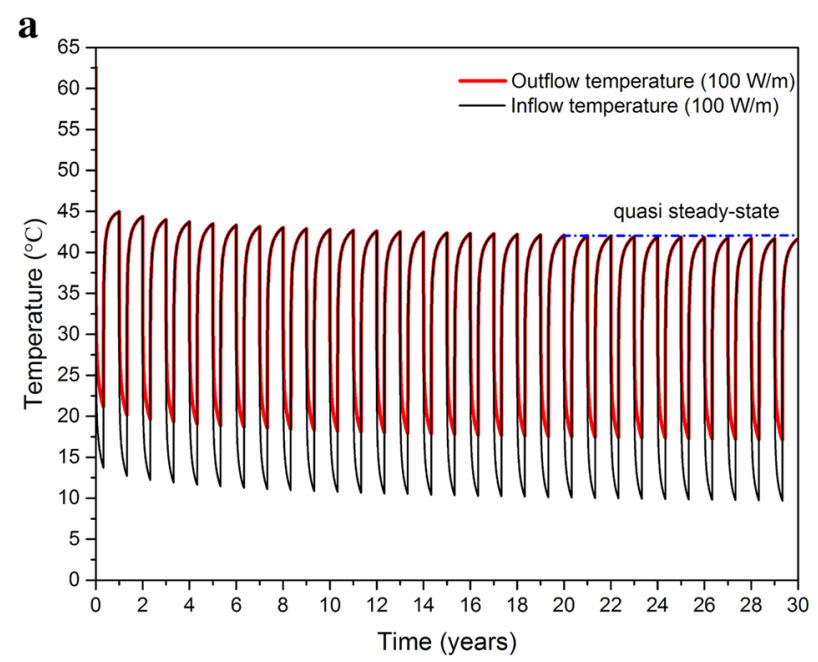

b

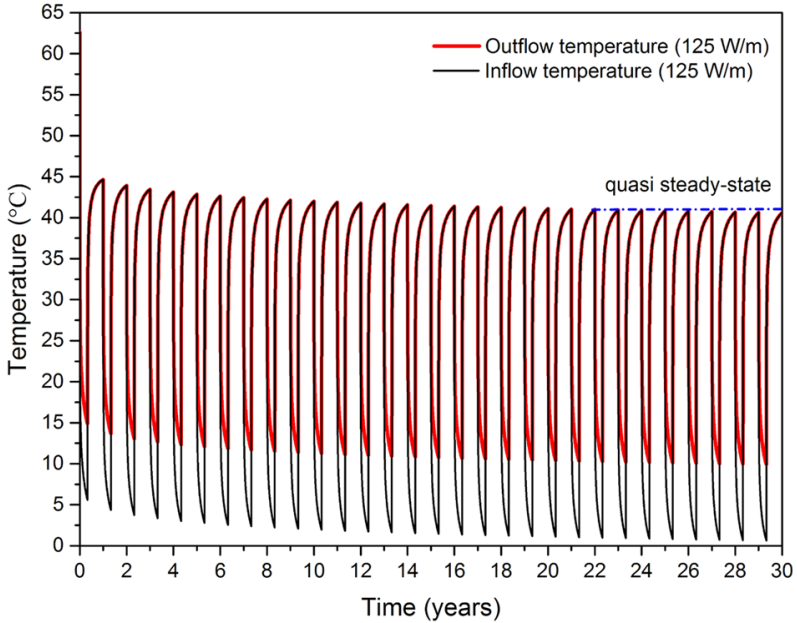

Fig. 11 Inflow and outflow temperature in the 30-year scenario, with specific heat extraction rate of a $100 \mathrm{~W}$ $\mathrm{m}^{-1} \mathbf{b} 125 \mathrm{~W} \mathrm{~m}^{-1}$

be kept at around $17.2{ }^{\circ} \mathrm{C}$. It is thus safe to conclude that a specific heat exchange rate of $100 \mathrm{~W} \mathrm{~m}^{-1}$ can be sustainably achieved on such a DBHE system for even longer period of time. When the thermal load increases to $125 \mathrm{~W} \mathrm{~m}^{-1}$, the minimum inflow temperature will be approaching $0{ }^{\circ} \mathrm{C}$ (cf. Fig. 11b) after about 20 years of operation. When this happens, the heat pump must be already operating at a very low efficiency and will not be economical. But it is noticeable that the outflow temperature can still reach $9.93^{\circ} \mathrm{C}$; in other words, there is still space to operate as long as the thermal load on the DBHE was kept the same.

\section{Efficiency analysis}

In the DBHE system, due to the presence of deep boreholes and long pipelines, the hydraulic loss is considerably higher than the shallow BHE system. Therefore, when analyzing the system efficiency, it is vital to include the electricity consumption by the circulating pump. With this fact in mind, the coefficient of system performance is defined 
in Eq. 11, which is the ratio of total electricity consumption over the amount of thermal energy supplied to the building. Assuming the outflow temperature of the DBHE is $20{ }^{\circ} \mathrm{C}$ with the baseline parameters presented in Table 1, the COP of heat pump equals to 5.585 according to Eq. 10, i.e., the electricity consumed by the heat pump accounts for $56706.65 \mathrm{~W}$. Meanwhile, there will be a electricity consumption of $6943 \mathrm{~W}$ required by the circulating pump, which is calculated by Eq. 12 considering the hydraulic loss in annulus and inner pipe. By comparing the two types of electricity consumption, it can be seen that the circulating pump will actually consume $12.24 \%$ of the total electricity needed by the entire system. When the above information is plugged into Eq. 11, it can be found that the calculated CSP value will be 0.61 less than the COP. Over the entire life span of the DBHE system, the electricity consumed by the circulating pump is almost constant, while the heat pump consumption will be varied depending on the DBHE outflow temperature and the thermal load from the building. In general, as the DBHE outflow temperature is gradually dropping, the heat pump consumption will increase, and the percentage of circulating pump will decrease.

As mentioned above, the system will shut down in reality when the outflow temperature of the DBHE is below $4{ }^{\circ} \mathrm{C}$, meanwhile the temperature difference cannot be bigger than $4{ }^{\circ} \mathrm{C}$ if the outflow temperature is approaching $4{ }^{\circ} \mathrm{C}$. In other words, according to the parameters presented in this work, when the CSP is lower than 3.7 and COP of the heat pump is lower than 4.3 , then the system is very likely to shut down automatically.

Taking advantage of the simulated inflow and outflow temperature, the temperature recovery ratio of every year was also calculated and its evolution is plotted in Fig. 12 for analysis, along with the statistical distribution of CSP values over 30 years of operation. It can be found that the temperature recovery ratio is lower than $99.5 \%$ in the first 5 years, and gradually increases afterwards. After 30 years, this ratio stabilizes at $99.91 \%$ and $99.89 \%$ for the $100 \mathrm{~W} \mathrm{~m}^{-1}$ and $125 \mathrm{~W} \mathrm{~m}^{-1}$, respectively. The variation range of recovery ratio is within $0.03 \%$ in the last ten recovery seasons and it approaches $100 \%$ in both long-term scenarios, indicating that the heat energy extracted during heating season is nearly fully recovered. It can be also calculated that over 30 years' operation, the

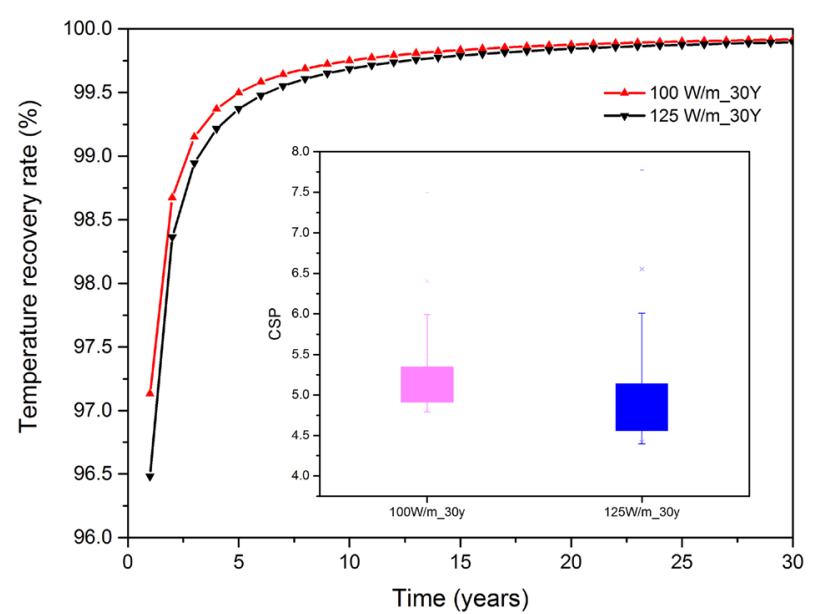

Fig. 12 Ratio of outflow temperature recovery and the corresponding CSP distribution over 30 years of operation 
average CSP with $100 \mathrm{~W} \mathrm{~m}^{-1}$ specific heat extraction rate will be 0.24 higher than that in the $125 \mathrm{~W} \mathrm{~m}^{-1}$ case.

\section{Conclusions}

Novelty

As stated in the introduction part, the motivation of this work was to investigate factors that influence the performance and sustainability of the DBHE system. The target was achieved by constructing numerical models with the OpenGeoSys software and simulating it with parameters obtained from a pilot project in China. The numerical result was firstly verified against analytical solution and further analyzed to quantify the heat flux variation over depth. Following this methodology, key parameters of interest were varied in the model in order to reveal their impact on the short-term performance, as well as the long-term sustainability. The combined impact was integrated into a CSP value, which was proposed as an index to measure the efficiency of the DBHE system.

\section{Main findings}

Among all the parameters, the soil thermal conductivity is the most important parameter determining the system performance, as the sensible heat stored in soil is the main energy source. The modeling result also found that the performance of the DBHE system can be improved by substituting the inner pipe with thermally insulated material. For the outer pipe, its thermal conductivity has only limited effect, while the application of thermally enhanced grout material will considerably improve the performance of the system. In locations where the averaged geothermal gradient is $0.04{ }^{\circ} \mathrm{C} \mathrm{m}^{-1}$, the sustainable specific heat extraction rate is calculated to be more than $150 \mathrm{~W} \mathrm{~m}^{-1}$ but smaller than $200 \mathrm{~W} \mathrm{~m}^{-1}$.

In the long-term scenarios, the sustainability of the system is constrained by the lowest outflow temperature of the DBHE. The outflow temperature should be controlled higher than $4{ }^{\circ} \mathrm{C}$, which provides acceptable efficiency of the heat pump. At the same time, the lowest inflow temperature of the DBHE cannot be $0{ }^{\circ} \mathrm{C}$, which is restricted by the circulating fluid and heat pump capacity. During the first 20 years of operation, the lowest outflow temperature of the DBHE quickly decreases in the first 7 to 8 years, and then gradually stabilizes after 10 years.

In modeling scenarios where the groundwater flow was considered, the outflow temperature of the DBHE barely changed. In other words, the performance and sustainability of the DBHE system are not affected by the groundwater flow, as the aquifers have only a small percentage penetrated by the DBHE. By calculation of the CSP value, the efficiency of the DBHE system can be quantified. A conclusion can be drawn that the lower threshold of the system efficiency is at a CSP value of 3.7, which corresponds to a heat pump COP of 4.3. When the system is operating below this threshold, it is very likely to be shut down due to low-temperature protection mechanism. However, it should be noticed that the CSP value strongly depends on the pipe structure and flow rate of circulating fluid.

\section{Implications and outlook}

The performance and sustainability of the DBHE system can be numerically simulated and predicted as long as there are enough site parameters accurately measured. With the specific heat extraction rate of $150 \mathrm{~W} \mathrm{~m}^{-1}$, although a $2.6-\mathrm{km}$ DBHE can supply heating to 
building surface area of $11,143 \mathrm{~m}^{2}$, it can only satisfy the heat demand of around 111 apartments with heating demand of $35 \mathrm{~W} \mathrm{~m}^{-12}$. Therefore, in a typical neighborhood located in densely populated urban areas, the heat pump needs to be coupled with several DBHEs. It is a challenge to simulate the complex interaction of such systems with several DBHEs and the connecting pipe network. This will be a topic for future investigation.

\section{List of symbols}

\section{Roman letters}

$\dot{Q}$ : thermal power $\left(M L^{2} T^{-3}\right)$; $c$ : specific heat capacity $\left(L^{2} T^{-2} \Theta^{-1}\right) ; D$ : diameter $(L) ; H$ : thermal sink/source term $\left(M L^{-1} T^{-3}\right) ; L$ : borehole length $(L)$; $P$ : pressure $\left(M L^{-1} T^{-2}\right)$; $Q$ : flow rate $\left(L^{3} T^{-1}\right) ; q_{n}$ : normal heat flux $\left(M T^{-3}\right) ; r$ : radius $(L)$; Re: Reynolds number (1); $T$ : temperature $(\Theta)$; $t$ : pipe wall thickness $(L)$; $v$ : velocity $\left(L T^{-1}\right) ; W$ : electricity $\left(M L^{2} T^{-3}\right)$.

\section{Greek letters}

$\beta$ : thermal expansion coefficient $\left(\Theta^{-1}\right) ; \epsilon$ : soil porosity $(1) ; \eta$ : efficiency of the circulating pump (1); $\Gamma$ : boundary; $\Lambda$ : tensor of thermal hydrodynamic dispersion $\left(M L T^{-3} \Theta^{-1}\right)$; $\lambda$ : thermal conductivity $\left(M L T^{-3} \Theta^{-1}\right)$; $\mu$ : viscosity $\left(M L^{-1} T^{-1}\right)$; $\Omega$ : domain; $\Phi$ : heat exchange coefficient $\left(M T^{-3} \Theta^{-1}\right) ; \rho$ : density $\left(M L^{-3}\right)$.

\section{Subscripts}

b: borehole; cp: circulating pump; f: fluid in the soil; ff: between inflow and outflow; fig: between inflow and grout; g: grout; gs: between grout and soil; h: hydraulic; hp: heat pump; i: inner pipe; o: outer pipe; r: circulating fluid (refrigerant); s: soil

\footnotetext{
Acknowledgements

Funding for the project was provided by the German Federal Ministry of Economic Affairs and Energy (BMWi) under Grant No. 03ET6122B ("ANGUS II: Impacts of the use of the geological subsurface for thermal, electrical or material energy storage in the context of transition to renewable energy sources - Integration of subsurface storage technologies into the energy system transformation using the example of Schleswig-Holstein as a model area") and is gratefully acknowledged. The research was supported as part of the GEMex project funded by the European Union's Horizon 2020 programme for Research and Innovation under Grant agreement No. 727550. Also, the first author (Chaofan Chen) would like to acknowledge the financial support from the China Scholarship Council (CSC) for his Ph.D. study in Germany.
}

\section{Authors' contributions}

This study is part of the Ph.D work of CC supervised by HS and OK. DN constructed the data structure for the DBHE feature in the OGS software. YK provided fundamental parameters of the DBHE system from northern China. KT offered suggestions regarding COP of heat pump and references of calculating CSP value. All authors read and approved the final manuscript.

\section{Availability of data and materials}

The DBHE modeling feature presented in this work has been included in the OpenGeoSys (OGS) software since version 6.2. Interested readers may obtain source code and corresponding benchmarks from the OGS website https://www. opengeosys.org/.

Competing interests

The authors declare that they have no competing interests.

\section{Author details}

${ }^{1}$ Helmholtz Centre for Environmental Research (UFZ), Permoserstr. 15, 04318 Leipzig, Germany. ${ }^{2}$ Applied Environmental Systems Analysis, Dresden University of Technology, 01069 Dresden, Germany. ${ }^{3}$ Freiberg University of Mining and Technology, 09599 Freiberg, Germany. ${ }^{4}$ Institute of Geology and Geophysics, Chinese Academy of Sciences, Beijing 100029, China. ${ }^{5}$ China University of Mining and Technology (Beijing), Beijing 100083, China. ${ }^{6}$ Department of Environmental Sciences, University of California, Riverside, CA 92521, USA. 
References

Acuña J, Palm B. Distributed thermal response tests on pipe-in-pipe borehole heat exchangers. Appl Energy. 2013;109:312-20.

Al-Khoury R, Kölbel T, Schramedei R. Efficient numerical modeling of borehole heat exchangers. Comput Geosci. 2010;36(10):1301-15.

Beier RA, Holloway WA. Changes in the thermal performance of horizontal boreholes with time. Appl Therm Eng. 2015;78:1-8. Beier RA, Acuña J, Mogensen P, Palm B. Transient heat transfer in a coaxial borehole heat exchanger. Geothermics. 2014;51:470-82.

Bu X, Ma W, Li H. Geothermal energy production utilizing abandoned oil and gas wells. Renew Energy. 2012;41:80-5.

Cai W, Wang F, Liu J, Wang Z, Ma Z. Experimental and numerical investigation of heat transfer performance and sustainability of deep borehole heat exchangers coupled with ground source heat pump systems. Appl Therm Eng. 2018;149:975-86.

Casasso A, Sethi R. Efficiency of closed loop geothermal heat pumps: a sensitivity analysis. Renew Energy. 2014;62:737-46.

Cui Y, Zhu J, Twaha S, Riffat S. A comprehensive review on 2D and 3D models of vertical ground heat exchangers. Renew Sustain Energy Rev. 2018;94:84-114.

Desmedt J, Van Bael J, Hoes H, Robeyn N. Experimental performance of borehole heat exchangers and grouting materials for ground source heat pumps. Int J Energy Res. 2012;36(13):1238-46.

FEFLOW: finite element modeling of flow, mass and heat transport in porous and fractured media. Berlin: Springer Science \& Business Media; 2013.

Diersch HJ, Bauer D, Heidemann W, RühaakW, Schätzl P. Finite element modeling of borehole heat exchanger systems: part 1. Fundamentals. Comput Geosci. 2011a;37(8):1122-35.

Diersch HJ, Bauer D, Heidemann W, RühaakW, Schätzl P. Finite element modeling of borehole heat exchanger systems: part 2. Numerical simulation. Comput Geosci. 2011b:37(8):1136-47.

Dijkshoorn L, Speer S, Pechnig R. Measurements and design calculations for a deep coaxial borehole heat exchanger in Aachen, Germany. Int J Geophys. 2013. https://doi.org/10.1155/2013/916541.

Falcone G, Liu X, Okech RR, Seyidov F, Teodoriu C. Assessment of deep geothermal energy exploitation methods: the need for novel single-well solutions. Energy. 2018;160:54-63.

Fang L, Diao N, Shao Z, Zhu K, Fang Z. A computationally efficient numerical model for heat transfer simulation of deep borehole heat exchangers. Energy Build. 2018;167:79-88.

Galgaro A, Farina Z, Emmi G, De Carli M. Feasibility analysis of a borehole heat exchanger (BHE) array to be installed in high geothermal flux area: the case of the Euganean Thermal Basin, Italy. Renew Energy. 2015;78:93-104.

Gordon D, Bolisetti T, Ting DS, Reitsma S. A physical and semi-analytical comparison between coaxial bhe designs considering various piping materials. Energy. 2017;141:1610-21.

Hein P, Kolditz O, Görke UJ, Bucher A, Shao H. A numerical study on the sustainability and efficiency of borehole heat exchanger coupled ground source heat pump systems. Appl Therm Eng. 2016a;100:421-33.

Hein P, Zhu K, Bucher A, Kolditz O, Pang Z, Shao H. Quantification of exploitable shallow geothermal energy by using borehole heat exchanger coupled ground source heat pump systems. Energy Convers Manag. 2016b;127:80-9.

Holmberg H, Acuña J, Næss E, Sønju OK. Thermal evaluation of coaxial deep borehole heat exchangers. Renew Energy. 2016:97:65-76.

Kahraman A, Çelebi A. Investigation of the performance of a heat pump using waste water as a heat source. Energies 2009:2(3):697-713.

Kohl T, Brenni R, Eugster W. System performance of a deep borehole heat exchanger. Geothermics. 2002;31 (6):687-708.

Kolditz O, Bauer S, Bilke L, Böttcher N, Delfs JO, Fischer T, Görke UJ, Kalbacher T, Kosakowski G, McDermott C. Opengeosys: an open-source initiative for numerical simulation of thermo-hydro-mechanical/chemical (THM/C) processes in porous media. Environ Earth Sci. 2012:67(2):589-99.

Kong YL, Chen CF, Shao HB, Pang ZH, Xiong LP, Wang JY. Principle and capacity quantification of deep-borehole heat exchangers. Chin J Geophys. 2017:60(12):4741-52.

Lazzari S, Priarone A, Zanchini E. Long-term performance of bhe (borehole heat exchanger) fields with negligible groundwater movement. Energy. 2010;35(12):4966-74.

Le Lous M, Larroque F, Dupuy A, Moignard A. Thermal performance of a deep borehole heat exchanger: insights from a synthetic coupled heat and flow model. Geothermics. 2015;57:157-72.

Lhendup T, Aye L, Fuller RJ. In-situ measurement of borehole thermal properties in melbourne. Appl Therm Eng 2014;73(1):287-95

Li M, Lai AC. Review of analytical models for heat transfer by vertical ground heat exchangers (GHEs): a perspective of time and space scales. Appl Energy. 2015;151:178-91.

Ni L, Dong J, Yao Y, Shen C, Qv D, Zhang X. A review of heat pump systems for heating and cooling of buildings in china in the last decade. Renew Energy. 2015;84:30-45.

Rivera JA, Blum P, Bayer P. A finite line source model with cauchy-type top boundary conditions for simulating near surface effects on borehole heat exchangers. Energy. 2016;98:50-63.

Shao H, Hein P, Sachse A, Kolditz O. Geoenergy modeling II: shallow geothermal systems. Berlin: Springer; 2016.

Shi Y, Song X, Li G, Yang R, Shen Z, Lyu Z. Numerical investigation on the reservoir heat production capacity of a downhole heat exchanger geothermal system. Geothermics. 2018;72:163-9.

Soldo V, Borović S, Lepoša L, Boban L. Comparison of different methods for ground thermal properties determination in a clastic sedimentary environment. Geothermics. 2016;61:1-11.

Tang F, Nowamooz H. Long-term performance of a shallow borehole heat exchanger installed in a geothermal field of alsace region. Renew Energy. 2018;128:210-22.

Wagner V, Bayer P, Bisch G, Kübert M, Blum P. Hydraulic characterization of aquifers by thermal response testing: validation by large-scale tank and field experiments. Water Resour Res. 2014;50(1):71-85.

Wang Z, Wang F, Liu J, Ma Z, Han E, Song M. Field test and numerical investigation on the heat transfer characteristics and optimal design of the heat exchangers of a deep borehole ground source heat pump system. Energy Convers Manag. 2017;153:603-15. 
Welsch B, Rühaak W, Schulte DO, Bär K, Sass I. Characteristics of medium deep borehole thermal energy storage. Int J Energy Res. 2016;40(13):1855-68.

Wu Q, Tu K, Sun H, Chen C. Investigation on the sustainability and efficiency of single-well circulation (SWC) groundwater heat pump systems. Renew Energy. 2019;130:656-66.

Zhang W, Yang H, Lu L, Fang Z. Investigation on influential factors of engineering design of geothermal heat exchangers. Appl Therm Eng. 2015;84:310-9.

Zheng T, Shao H, Schelenz S, Hein P, Vienken T, Pang Z, Kolditz O, Nagel T. Efficiency and economic analysis of utilizing latent heat from groundwater freezing in the context of borehole heat exchanger coupled ground source heat pump systems. Appl Therm Eng. 2016;105:314-26.

\section{Publisher's Note}

Springer Nature remains neutral with regard to jurisdictional claims in published maps and institutional affiliations.

Submit your manuscript to a SpringerOpen ${ }^{\circ}$ journal and benefit from:

Convenient online submission

- Rigorous peer review

- Open access: articles freely available online

- High visibility within the field

- Retaining the copyright to your article

Submit your next manuscript at $\boldsymbol{\nabla}$ springeropen.com 